\title{
COMPARATIVE IMMUNOGENICITY AND EFFICACY STUDIES WITH ORAL RABIES VIRUS VACCINE SAD P5/88 IN RACCOON DOGS AND RED FOXES
}

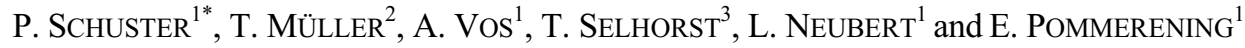 \\ ${ }^{1}$ IDT, PSF 214, 06855 Rosslau, Germany; ${ }^{2}$ Institute of Epidemiological Diagnostics, \\ Federal Research Centre for Virus Diseases of Animals, Wusterhausen, Germany; ${ }^{3}$ WHO \\ Collaborating Centre for Rabies Surveillance and Research, Wusterhausen, Germany
}

(Received November 27, 2000; accepted February 8, 2001)

\begin{abstract}
A comparative study of immunogenicity and efficacy of the oral rabies virus vaccine SAD P5/88 in raccoon dogs and foxes was conducted. The raccoon dogs received $10^{6.9}(\mathrm{n}=6), 10^{6.3}(\mathrm{n}=6)$ or $10^{5.7}$ FFU SAD P5/88 $(\mathrm{n}=5)$ by direct oral application, and subsequently all animals seroconverted. The foxes received $10^{7.2}(\mathrm{n}=4), 10^{6.2}(\mathrm{n}=4), 10^{5.2}(\mathrm{n}=4)$ and $10^{4.2}$ FFU SAD P5/88 $(\mathrm{n}=5)$ by the same route. On days 106 and 196 post vaccination 10 raccoon dogs and 16 foxes were challenged with a relevant street virus, respectively. All 10 raccoon dogs vaccinated with $10^{6.3}(\mathrm{n}=5)$ or $10^{5.7}$ FFU SAD P5/88 $(\mathrm{n}=5)$ survived the challenge, whereas all control animals $(n=5)$ died of rabies. Two foxes vaccinated with $10^{4.2}$ FFU and one fox vaccinated with $10^{5.2}$ FFU died of rabies on day 7,17 and 12 post infection, respectively. Also all control foxes succumbed to rabies. Our findings demonstrate that SAD P5/88 is not only an effective vaccine for oral vaccination of foxes but also for that of raccoon dogs.
\end{abstract}

Key words: Raccoon dog, fox, rabies, oral vaccination, SAD P5/88

Until recently, the red fox (Vulpes vulpes) was considered the major reservoir species of rabies in Europe. Consequently, the development of suitable oral rabies virus vaccines was rightfully focused on this animal species. More than 20 years after the first oral vaccination campaign in Switzerland, the rabies situation has changed drastically in Europe (Stöhr and Meslin, 1996; Müller and Schlüter, 1998). Especially in Western and Central Europe the number of rabies cases has decreased considerably; in some of these regions or countries terrestrial wildlife rabies has been completely eradicated (Vos et al., 2000). Nowadays, most rabies cases are reported from Eastern Europe. Oral vaccination is becoming more and more the method of choice in controlling wildlife rabies also in that part of the continent. However, in many of these countries not only the red fox but also another canid species, the raccoon dog (Nyctereutes procyonoides), forms a reservoir and vector species for rabies. The raccoon dog originates from Eastern Asia,

*Corresponding author; E-mail: peter.schuster@idt-direct.de; Fax: +49 34901885797 
but was introduced as a fur animal to the northwest of the former Soviet Union (Nowak, 1984). Following a rapid extension of their range, they arrived in Finland in 1935 and in southern Sweden in 1945. From Russia they also spread to the Baltic nations and Belarus, and subsequently to Romania (1951), Poland (1955), Czechoslovakia (1959), Hungary (1961), Germany (1961), Austria (1962) and Bulgaria (1967) (Lever, 1985; Nowak, 1993). Further incidental reports have been made from e.g. Denmark, the Netherlands and France (Nowak, 1984; Lever, 1985). This highly adaptive animal species with its high reproductive output has established itself firmly among the European native fauna in a naturalized habitat encompassing almost 1.5 million $\mathrm{km}^{2}$ since 1935 (Kauhala, 1992; Nowak, 1993). Rabies cases in raccoon dogs have been reported from Poland, Germany, Finland, Russia, Latvia, Lithuania, Estonia, Belarus and the Czech Republic (source: Rabies Bulletin Europe 1978-1998).

Between 1978 and 1999, 1826 rabies cases were reported in raccoon dogs from Poland (source: Rabies Bulletin Europe 1978-1999). Rabies in raccoon dogs is endemic also in the Baltic countries: Latvia, Estonia and Lithuania reported 258, 218 and 213 rabies cases in raccoon dogs, respectively, between 1992 and 1999 (source: Rabies Bulletin Europe 1992-1999). Oral vaccination campaigns in these countries should not only be aimed at controlling fox rabies but raccoon dog rabies as well. For this purpose, the suitability of oral rabies virus vaccines used in regions where the raccoon dog is present must also be examined for this animal species. In this paper experimental studies on the immunogenicity and efficacy of the oral rabies virus vaccine SAD P5/88 in raccoon dogs and foxes are described and compared.

\section{Materials and methods}

The SAD strain (Street-Alabama-Dufferin) was isolated from a rabid dog at the Centers for Diseases Control, USA, in 1935, and propagated by passaging in mouse brain cells and subsequently adapted to BHK 21 cells (Blancou and Meslin, 1996). The SAD P5/88 rabies virus was developed via adaptation of the SAD Berne strain to a higher producer cell line, BHK 21/Potsdam clone 5 (Sinnecker et al., 1990).

Seventeen raccoon dogs and 17 foxes, all farm-bred animals, were vaccinated with different concentrations of SAD P5/88 vaccine virus. All animals were marked and housed individually for identification purposes and tested negative for rabies neutralizing antibodies prior to vaccination (B0). These and subsequent serum samples were evaluated by the Rapid Fluorescence Focus Inhibition Test (RFFIT) (Smith et al., 1973), with the modifications of that method as described by Cox and Schneider (1976). The rabies virus neutralizing antibody titres were converted to International Units (IU). 
The following amounts of SAD P5/88 were administered to the raccoon dogs by direct oral application: $10^{6.9} \mathrm{FFU}(\mathrm{n}=6), 10^{6.3} \mathrm{FFU}(\mathrm{n}=6)$ and $10^{5.7} \mathrm{FFU}$ SAD P5/88 $(\mathrm{n}=5)$. The foxes received $10^{7.2} \mathrm{FFU}(\mathrm{n}=4), 10^{6.2} \mathrm{FFU}(\mathrm{n}=4)$, $10^{5.2} \mathrm{FFU}(\mathrm{n}=4)$ or $10^{4.2} \mathrm{FFU}$ SAD P5/88 $(\mathrm{n}=5)$ by the same route. The raccoon dogs were bled on days 21 (B1) and 83 (B2) post vaccination, and blood samples of the foxes were collected on days 21 (B1), 56 (B2) and 196 (B3) post vaccination.

The vaccinated and 7 control foxes were challenged on day 196 post vaccination by intramuscular (i.m.) administration of $1 \mathrm{ml}\left(10^{4.8} \mathrm{LD}_{50}\right)$ of a challenge virus isolated from a rabid fox (CVS 240190) into the m. masseter. All surviving animals were euthanized 90 days post infection. Furthermore, the 10 raccoon dogs vaccinated with $10^{6.3}(\mathrm{n}=5)$ or $10^{5.7}$ FFU SAD P5/88 $(\mathrm{n}=5)$ and 5 control animals were challenged 106 days post vaccination by i.m. administration of $1.0 \mathrm{ml}$ $\left(10^{4.2} \mathrm{LD}_{50}\right)$ of a canid challenge virus into the $\mathrm{m}$. masseter. While no challenge virus isolated from a raccoon dog was available, a challenge virus was selected with a high pathogenicity in order to achieve $100 \%$ mortality of the control animals. The challenge virus (CVS/USA/TX coyote/ 295/R/061893) used was isolated from the salivary glands from a rabid coyote (Canis latrans) and obtained from the Centers for Disease Control and Prevention in Atlanta, GA, USA.

The surviving raccoon dogs were euthanized 90 days post infection. To prove the presence of viral antigen, from all challenged raccoon dogs and foxes, the brain was collected immediately after the death of the animals and examined for the presence of rabies virus by the fluorescence antibody test (FAT) (Dean et al., 1996). Also, a blood sample was collected from all surviving animals at the end of the challenge test. Animal experimentation was performed according to the German Animal Welfare Act (Tierschutzgesetz) of 25 May 1998. The experimental design of the challenge test was approved by the competent authorities of Germany.

\section{Results}

The immune response of the raccoon dogs is shown in Table 1. All animals developed high levels of rabies virus neutralizing antibodies. The Geometric Mean Titre (GMT) of the B1 and B2 blood samples was 20.37 and $28.46 \mathrm{IU} / \mathrm{ml}$, respectively. No significant drop in rabies neutralizing antibody titre was observed between $\mathrm{B} 1$ and $\mathrm{B} 2$ in raccoon dogs (Wilcoxon test, $\mathrm{T}=62, \mathrm{n}=$ 17, n.s.). Also, no significant differences were observed in immune responses between the three different vaccination doses (Student's $t$-test). All of the vaccinated raccoon dogs survived the challenge, irrespective of the vaccination dose (Table 2). Meanwhile all control animals succumbed to rabies, on average, 11.2 days post infection (range: 10-13 days). No booster effect after administration of the challenge virus was observed in the surviving raccoon dogs (Wilcoxon test, $\mathrm{T}=25, \mathrm{n}=10$, n.s.). 
Table 1

Individual rabies neutralizing antibody titre (IU/ml), as determined by RFFIT, of the raccoon dogs inoculated with SAD P5/88 by direct oral application

\begin{tabular}{|c|c|c|c|c|c|}
\hline $\begin{array}{c}\text { Animal } \\
\text { no. }\end{array}$ & $\begin{array}{c}\text { Vaccine } \\
\text { dose } \\
(\mathrm{FFU})\end{array}$ & $\begin{array}{c}\text { B0 } \\
\text { prior to } \\
\text { vaccination }\end{array}$ & $\begin{array}{c}\text { B1 } \\
21 \text { days } \\
\text { post vaccination }\end{array}$ & $\begin{array}{c}\text { B2 } \\
83 \text { days } \\
\text { post vaccination }\end{array}$ & $\begin{array}{c}\text { B3 } \\
90 \text { days } \\
\text { post infection }\end{array}$ \\
\hline 1 & $10^{6.7}$ & $(-)$ & 16.96 & 14.29 & n. c. \\
\hline 2 & $10^{6.7}$ & $(-)$ & 34.54 & 64.68 & n. c. \\
\hline 3 & $10^{6.7}$ & $(-)$ & 48.87 & 23.17 & n. c. \\
\hline 4 & $10^{6.7}$ & $(-)$ & 37.90 & 25.12 & n. c. \\
\hline 5 & $10^{6.7}$ & $(-)$ & 32.00 & 74.80 & n. c. \\
\hline 6 & $10^{6.7}$ & $(-)$ & 44.84 & 116.70 & n. c. \\
\hline 7 & $10^{6.2}$ & $(-)$ & 16.89 & 14.76 & 28.36 \\
\hline 8 & $10^{6.2}$ & $(-)$ & 31.81 & 22.04 & 18.47 \\
\hline 9 & $10^{6.2}$ & $(-)$ & 3.04 & 12.69 & 9.65 \\
\hline 10 & $10^{6.2}$ & $(-)$ & 3.13 & 98.89 & 42.14 \\
\hline 11 & $10^{6.2}$ & $(-)$ & 46.45 & 16.06 & 14.74 \\
\hline 12 & $10^{6.2}$ & $(-)$ & 38.21 & 38.64 & n. c. \\
\hline 13 & $10^{5.6}$ & $(-)$ & 30.52 & 9.16 & 17.27 \\
\hline 14 & $10^{5.6}$ & $(-)$ & 32.07 & 15.92 & 36.48 \\
\hline 15 & $10^{5.6}$ & $(-)$ & 10.40 & 19.50 & 24.43 \\
\hline 16 & $10^{5.6}$ & $(-)$ & 39.91 & 117.67 & 79.12 \\
\hline 17 & $10^{5.6}$ & $(-)$ & 3.13 & 13.24 & 21.47 \\
\hline
\end{tabular}

Table 2

Summary of the immunogenicity studies (seroconversion rate) and challenge experiment (survival rate) with SAD P5/88 in raccoon dogs and foxes using different concentrations

\begin{tabular}{lccc}
\hline \multicolumn{1}{c}{ Animal } & Vaccine dose (FFU) & Seroconversion rate & Survival rate \\
\hline Raccoon dog & $10^{6.9}$ & $6 / 6$ & n.e. \\
Raccoon dog & $10^{6.3}$ & $6 / 6$ & $5 / 5$ \\
Raccoon dog & $10^{5.7}$ & $5 / 5$ & $5 / 5$ \\
Fox & $10^{7.2}$ & $4 / 4$ & $4 / 4$ \\
Fox & $10^{6.2}$ & $3 / 4$ & $3 / 3$ \\
Fox & $10^{5.2}$ & $3 / 4$ & $3 / 4$ \\
Fox & $10^{4.2}$ & $3 / 5$ & $3 / 5$ \\
\hline
\end{tabular}

n.e.: not examined

The immune response of the foxes is shown in Table 3. Four foxes did not seroconvert and in one of these animals (No. 7) a severe enteritis was diagnosed and the animal was subsequently euthanized on day 109 post vaccination. Of the 16 remaining foxes challenged, the three animals that did not seroconvert died of rabies 7 (No. 16), 12 (No. 10) and 17 days (No. 14) post infection as confirmed by FAT. No significant drop in rabies neutralizing antibody titre was observed be- 
tween B1 and B3 in foxes (Wilcoxon test, $\mathrm{T}=7, \mathrm{n}=8$, n.s.). Also, no booster effect after administration of the challenge virus in the surviving foxes was observed (Wilcoxon test, $\mathrm{T}=3, \mathrm{n}=7$, n.s.). The immune response (B1 and $\mathrm{B} 2$ ) of the raccoon dogs and foxes vaccinated with $10^{6.3}$ and $10^{6.2}$ FFU SAD P5/88 did not differ significantly (Student's $t$-test).

Table 3

Individual rabies neutralizing antibody titre (IU/ml), as determined by RFFIT, of the foxes inoculated with SAD P5/88 by direct oral application

\begin{tabular}{rcccccc}
\hline $\begin{array}{c}\text { Animal } \\
\text { no. }\end{array}$ & $\begin{array}{c}\text { Vaccine dose } \\
\text { (FFU) }\end{array}$ & $\begin{array}{c}\text { B0 } \\
\text { prior to } \\
\text { vaccination }\end{array}$ & $\begin{array}{c}\text { B1 days } \\
\text { post vacc. }\end{array}$ & $\begin{array}{c}\text { B2 } \\
56 \text { days } \\
\text { post vacc. }\end{array}$ & $\begin{array}{c}\text { B3 } \\
196 \text { days } \\
\text { post vacc. }\end{array}$ & $\begin{array}{c}\text { B4 } \\
134 \text { days } \\
\text { post infection }\end{array}$ \\
\hline 1 & $10^{7.2}$ & $(-)$ & 30.0 & 30.0 & 30.0 & 10.0 \\
2 & $10^{7.2}$ & $(-)$ & 30.0 & 30.0 & 10.0 & 10.0 \\
3 & $10^{7.2}$ & $(-)$ & 30.0 & 60.0 & 60.0 & 30.0 \\
4 & $10^{7.2}$ & $(-)$ & 10.0 & 20.0 & 30.0 & 20.0 \\
5 & $10^{6.2}$ & $(-)$ & 10.0 & 20.0 & 10.0 & 20.0 \\
6 & $10^{6.2}$ & $(-)$ & 10.0 & 30.0 & 30.0 & 30.0 \\
7 & $10^{6.2}$ & $(-)$ & $(-)$ & $(-)$ & died & 10.0 \\
8 & $10^{6.2}$ & $(-)$ & 10.0 & 30.0 & 30.0 & 10.0 \\
9 & $10^{5.2}$ & $(-)$ & 10.0 & 20.0 & $(-)$ & 6.7 \\
10 & $10^{5.2}$ & $(-)$ & $(-)$ & $(-)$ & 10.0 & 10.0 \\
11 & $10^{5.2}$ & $(-)$ & 10.0 & 30.0 & 20.0 & 10.0 \\
12 & $10^{5.2}$ & $(-)$ & 30.0 & n.e. & 20.0 & 20.0 \\
13 & $10^{4.2}$ & $(-)$ & 10.0 & n.e. & $(-)$ & died \\
14 & $10^{4.2}$ & $(-)$ & $(-)$ & $(-)$ & 20.0 & 20.0 \\
15 & $10^{4.2}$ & $(-)$ & 30.0 & 60.0 & $(-)$ & died \\
16 & $10^{4.2}$ & $(-)$ & $(-)$ & 60.0 & 20.0 & 20.0 \\
17 & $10^{4.2}$ & $(-)$ & 6.7 & 90.0 & & \\
\hline
\end{tabular}

n.e.: not examined

\section{Discussion}

The consequences of introducing animal species are often not clear from the start. Nowadays, half a century after its introduction, the raccoon dog can be considered an important reservoir species for rabies especially in Eastern Europe. Although oral vaccination campaigns in Europe were aimed at foxes, some experience already demonstrates that this novel approach can be used successfully for eradicating rabies in raccoon dogs. During a rabies outbreak in Finland in the late 1980 s $71 \%$ of all cases were reported in raccoon dogs. Vaccine baits were distributed in the infected area in 1988 and 1989; the last terrestrial wildlife rabies case in Finland was reported February 1989. Hence, it was shown that oral vaccination could eradicate and control raccoon dog rabies as well (Reinius, 1992).

To be able to assess the feasibility of oral vaccination in raccoon dogs, safety, immunogenicity and efficacy studies of available virus vaccines must be 
conducted in this target species. The high immunogenicity of SAD P5/88 in foxes was already known; during a relevant challenge experiment 28 out of 29

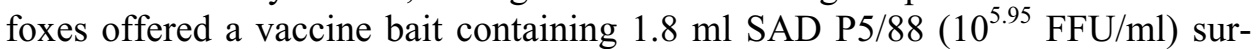
vived a rabies infection 260 days post vaccination (unpublished results). Hence, the minimum effective dose of SAD P5/88 for foxes has been set at $10^{6.2} \mathrm{FFU}$. In this study, it was demonstrated that all foxes vaccinated with this dose were protected against a rabies infection. Lower doses did not result in a $100 \%$ protection rate. Up till now, it was not known if this minimum dose of SAD P5/88 would be sufficient to immunize and protect raccoon dogs against rabies. The study presented in this paper did not only show that raccoon dogs vaccinated with $10^{6.2}$ FFU SAD P5/8 did develop high levels of rabies neutralizing antibodies and consequently survived a rabies challenge, but also demonstrated that raccoon dogs were also protected when vaccinated with a lower dose.

Hence, it can be concluded that SAD P5/88 is a vaccine virus highly suitable for oral vaccination, especially in areas where foxes and raccoon dogs are both present.

\section{References}

Blancou, J. and Meslin, F.-X. (1996): Modified live-virus rabies vaccines for oral immunization of carnivores. In: Meslin, F.-X., Kaplan, M. M. and Koprowski, H. (eds) Laboratory Techniques in Rabies. 4th edition. World Health Organization, Geneva. pp. 324-337.

Cox, J. H. and Schneider, L. G. (1976): Prophylactic immunization of humans against rabies by intradermal inoculation of human diploid cell culture vaccine. J. Clin. Microbiol. 3, 86-101.

Dean, D. J., Abelseth, M. K. and Athanasiu, P. (1996): The fluorescence antibody test. In: Meslin, F.-X., Kaplan, M. M. and Koprowski, H. (eds) Laboratory Techniques in Rabies. 4th edition. World Health Organization, Geneva. pp. 88-93.

Kauhala, K. (1992): Ecological characteristics of the raccoon dog in Finland. Dissertation, University of Helsinki, Finland.

Lever, C. (1985): Naturalized Mammals of the World. Longman Group Ltd., Essex.

Müller, T. and Schlüter, H. (1998): Oral immunization of red foxes (Vulpes vulpes) in Europe - A review. J. Etlik Vet. Microbiol. 9, 35-59.

Nowak, E. (1984): Verbreitungs- und Bestandsentwicklung des Marderhundes, Nyctereutes procyonoides (Gray, 1834) in Europa. Z. Jagdwiss. 30, 137-154.

Nowak, E. (1993): Nyctereutes procyonoides Gray, 1834 - Marderhund. In: Stubbe, M. and Krapp, F. (eds) Handbuch der Säugetiere Europas, Band 5/I - Raubsäuger. Aula-Verlag, Wiesbaden. pp. 215-248.

Reinius, S. (1992): Epidemiology of fox/raccoon dog rabies in Finland. In: Bögel, K., Meslin, F.X. and Kaplan, M. (eds) Wildlife Rabies Control. Wells Medical Ltd., Kent. pp. 32-34.

Sinnecker, H., Apitzsch, H., Berndt, D., Schrader, C., Gogolin, J. and Egert, J. (1990): Die Entwicklung des Tollwutlebendimpfvirus SAD/Postdam 5/88 zur oralen Fuchsimpfung sowie seine Charakterisierung am Mausmodel. Mh. Vet. Med. 45, 77-78.

Smith, J. S., Yager, P. A. and Baer, G. M. (1973): A rapid reproducible test for determining rabies neutralizing antibody. Bull. World Health Organ. 48, 535-541.

Stöhr, K. and Meslin, F.-X. (1996): Progress and setbacks in the oral immunisation of foxes against rabies in Europe. Vet. Rec. 139, 32-35.

Vos, A., Müller, T., Schuster, P., Schlüter, H. and Neubert, A. (2000): Oral vaccination of foxes against rabies with SAD B19 in Europe, 1983-1998: A review. Vet. Bull. 70, 1-6. 